\title{
Incorporation of acrylate based spiropyran monoliths in micro-fluidic devices for photo-controlled electroosmotic flow
}

\author{
Silvia Scarmagnani, Zarah Walsh, Fernando Benito-Lopez, Mirek Macka, Brett Paull and Dermot \\ Diamond* \\ CLARITY and ISSC, National Centre for Sensor Research, School of Chemical Sciences, Dublin City University, \\ Glasnevin, Dublin 9, Ireland \\ *dermot.diamond@dcu.ie
}

Spiropyran derivatives belong to a well-known family of photochromic compounds that are able to change their physical and chemical properties under external light modulation ${ }^{1}$. Spiropyran can switch between a non-polar spiro form (SP) and a zwitterionic merocyanine form (MC) that can be subject to protonation.

It has been demonstrated that spiropyran based monoliths in an acidic environment $\left(10^{-3} \mathrm{M} \mathrm{HCl}\right)$ can generate an electroosmotic flow (EOF) in the presence of an applied voltage and that the generated flow can be modulated by the means of light irradiation.

The first example of a spiropyran monolith which can be used as a photo-controlled electroosmotic pump (EOP) was recently presented by Walsh et al. and it is based on a vinyl spiropyran monomer ${ }^{2,3}$.

In order to investigate new spiropyran monoliths that can be applied as EOPs within a micro-fluidic chip, we now report a new monolith based on an acrylated spiropyran monomer which is particularly sensitive to protonation and in acidic environment it readily converts to the protonated $\mathrm{MC}\left(\mathrm{MC}-\mathrm{H}^{+}\right)$ form which produces a highly positively charged surface that can be re-converted to the uncharged SP form by white light exposure ${ }^{4}$.

In the presence of $10^{-3} \mathrm{M} \mathrm{HCl}$, the $\mathrm{MC}-\mathrm{H}^{+}$form is generated and it produces a highly charged surface which enables a relatively high flow rate (up to $1.6 \mu \mathrm{l} / \mathrm{min}$ ), under electroosmotic conditions, due to the more effective formation of the necessary charged double layer.

When the monolith is then exposed to white light, the concentration of $\mathrm{MC}-\mathrm{H}^{+}$form decreases due to the conversion back to the neutral SP form with a consequent $10 \%$ to $19 \%$ reduction of the EOF. The process is reversible and removal of the light source results in a flow increase.

Clearly this spiropyran monolith can act as an EOP, in which the flow can be modulated to some degree through the presence or absence of light. This ability to profoundly alter such properties using light has very significant implications for science, as it could lead to the development of a control over column retention or liquid flow using light.

Acknowledgement The authors would like to acknowledge support for this research by Science Foundation Ireland under the 'Adaptive Information Cluster' award (SFI 03/IN.3/1361 and 07/RPF/MASF812) and the Irish Separation Science Cluster Award (Grant Number 08/SRC/B1412) and the Marie Curie Excellence Grants and Funding (MEXT-CT-2004-014361).

\section{Reference}

(1) Dürr, H.; Bouas, L. H. Photochromism - molecules and systems; Elsevier: Amsterdam, Boston, 2003.

(2) Walsh, Z.; Scarmagnani, S.; Norton, M.; Benito-Lopez, F.; Nie, F.-Q.; Abele, S.; Svec, F.; Diamond, D.; Paull, B.; Macka, M. IICS 2009 - 21st International Ion Chromatography Symposium 21-24 September Malahide (Dublin), 2009.

(3) Walsh, Z.; Scarmagnani, S.; Benito-Lopez, F.; Abele, S.; Nie, F.-Q.; Byrne, R.; Slater, C.; Diamond, D.; Paull, B.; Macka, M. Sensors and Actuators B: Chemical 2009, Submitted.

(4) Szilagyi, A.; Sumaru, K.; Sugiura, S.; Takagi, T.; Shinbo, T.; Zrinyi, M.; Kanamori, T. Chemistry of Materials 2007, 19, 2730-2732. 